Published in: Current Climate Change Reports, 2018

\title{
Plants and Drought in a Changing Climate
}

Abigail L. S. Swann ${ }^{1,2}$

${ }^{1}$ Department of Atmospheric Sciences, University of Washington, Box 351640, Seattle, WA 98195-1640

${ }^{2}$ Department of Biology, University of Washington

Corresponding author email: aswann@uw.edu

ORCID ID: orcid.org/0000-0001-8513-1074

Keywords: Drought; Global Warming; Climate Change; Hydrological Impact; Forest Mortality; Water Use Efficiency 


\section{Abstract}

Purpose of review Climate is changing in response to rising concentrations of atmospheric $\mathrm{CO}_{2}$ and it is commonly asserted that this will cause droughts to become more frequent and severe. However, different metrics of drought give diverging estimates of future impacts. I present a summary of the significant yet underappreciated influence that plant stomatal and growth responses to $\mathrm{CO}_{2}$ have on drought, and highlight new insights into the impacts of drought on plants in a warmer world.

Recent findings Plants influence the water availability on land, and thus reduce the duration and intensity of droughts under higher $\mathrm{CO}_{2}$ conditions. Plants are concurrently more vulnerable to mortality when droughts occur under hotter conditions.

Summary The frequency and severity of drought in the future depends on the response of plants to a changing climate - ignoring plant responses leads to over-prediction of drought.

Nonetheless, the impact of current frequencies of drought on plants could lead to higher mortality rates in the future as plants must withstand drought stress simultaneously with hotter temperatures.

\section{Introduction}

Climate is changing due to increasing concentrations of $\mathrm{CO}_{2}$ in the atmosphere. Hotter temperatures, changing rainfall patterns, and more frequent and severe droughts are commonly cited as impacts from greenhouse gas driven forcing [1]. Droughts are commonly defined as a deficit in supply of water, or supply of water relative to demand [2]. However, different drought metrics give diverging estimates of future drought conditions over land. This discrepancy arises from the multiple definitions of drought (from who's perspective is it a drought?) and also from uncertainty in the responses of both the physical and biological systems to climate forcing. In this review I discuss the competing factors that influence plant water needs and stress in the future (Fig. 1). Higher concentrations of $\mathrm{CO}_{2}$ have the ability to both boost growth of plants (which will lead to more water use) and increase their water use efficiency. These opposing factors compensate for one another, and the relative magnitude of these changes in water use determines the water needs of plants in a future climate, and thus the thresholds of drought occurrence. However, even with constant occurrence of drought, plants may experience more stress when droughts occur concurrent with hotter temperatures. The impact of future drought on plants critically depends on the balance of these factors, several of which remain highly uncertain. In this review I will first introduce drought from a plant's perspective and how we measure droughts currently, then discuss how droughts will change under future climate, how this is influenced by plants, and how plant stress and mortality is likely to respond.

\section{What is drought from a plant's perspective?}

Drought is, loosely speaking, characterized by a deficit in the supply of water [2]. The deficit could be relative to some defined normal conditions, or it could be relative to some demand for water. Each of these relative deficits is important from different perspectives. Systems that rely primarily on water input are sensitive to rainfall amounts that are low compared to normal (often called meteorological drought), while human systems relying on surface water supplies (i.e. rivers, lakes) are sensitive to the availability of surface water relative to demand from human consumption (often called hydrological drought). If we consider the perspective of a plant, the 
source of water is from the soil, and the demand for water is from the dryness of the atmosphere. Drought from a plant's perspective occurs when supply is unable to meet demand (often called agricultural or ecological drought) resulting in plant stress, potential damage to tissues, and if damage is extensive, mortality.

As climate changes, plants will contend with new and novel combinations of environmental conditions. Higher temperatures will increase biochemical rates in plants, at least to a point, but when extreme, may also increase stress. Changing humidity and water availability will alter plant photosynthetic rates, and the rate of gas exchange between plants and the atmosphere. And higher levels of atmospheric $\mathrm{CO}_{2}$ have the potential to increase plant photosynthesis while simultaneously allowing plants to lose less water to the atmosphere. These factors and many more, as well as the interactions between them, alter how much water plants need and subsequently, the stress that these plants experience. From the plant's perspective, it is only a drought if the plant is stressed. Thus, characterizing these many competing and interacting factors is necessary to assess drought occurrence and severity in a future climate.

\section{How do we assess drought in the present day?}

A number of different indices are used for operational assessment of current drought conditions and diagnostic assessment of past drought conditions. These indices are based either on supply alone, or on some change in supply relative to demand for water (Table 1).

Supply of water can be quantified using direct observations (e.g. precipitation) or derived from observations using empirical estimates of supply. Estimates of supply are typically made using some estimate of a water budget, with the goal of estimating soil moisture. In the Standardized Precipitation Index (SPI), for example, supply is determined using precipitation [3], while in the Palmer Drought Severity Index (PDSI) supply is determined using precipitation as well as an estimate of soil water holding capacity (demand is also considered for PDSI) $[4,5]$.

Demand for water is more challenging to characterize directly with observations, and so it is typically calculated from empirical estimates of the potential for water to evaporate, called the potential evapotranspiration (PET). PET represents the demand for water by the atmosphere, and can be calculated based on the total incoming radiation [6], using simple empirical relationships with temperature (i.e. [7]), or with more physically realistic approaches based on solving a surface energy budget (e.g. Penman-Monteith, [8,9]). However estimating the surface energy budget requires constraining plant transpiration in some way, and the relationship between plant transpiration and atmospheric demand is likely to change under higher $\mathrm{CO}_{2}$ conditions [10].

The supply of water to the land from the atmosphere is one aspect of drought, but not sufficient for assessing plant stress. Plants derive their supply of water from soil moisture in the rooting zone. Thus, estimates of drought impact on plants should include both changes in supply of water to the land surface, and the demand from the atmosphere. Drought indices that consider both supply and demand then combine the two parts to find how much and for how long the supply has been unable to meet the demand. Indices like PDSI were formulated with the intent of assessing drought stress experienced by plants [4]. They may do this adequately under the climate conditions to which they are normalized [5,11], however are frequently not appropriate for use in a changing climate [12] as discussed further below. 
Quantifying the supply relative to the demand is a water budget approach, which approximates the amount of water that is available to plants. The true water available to plants is determined by root zone available water, which is in turn a function of soil moisture in the rooting zone, root biomass able to access it, as well as soil properties including texture and depth (e.g. [13]). Given that soil moisture in the rooting zone represents the water actually potentially available to plants, this would be the preferred metric to follow. However, soil moisture is not widely observed, and modeled estimates for both the present day and the future vary widely [14]. Soil properties such as texture and depth are also important factors determining actual plant available water, with the sand and clay content of soil determining the ease at which roots can extract water from the soil matrix [15]. Soils are highly heterogeneous spatially, and with limited observations available it has proven difficult to constrain models, especially at global scales.

\section{Plant responses to a changing climate}

Concentrations of $\mathrm{CO}_{2}$ in the atmosphere are increasing due to human emissions, driving changes in climate through radiative forcing. Plants take up $\mathrm{CO}_{2}$ and convert it to sugars in the process of photosynthesis. Plants diffuse $\mathrm{CO}_{2}$ out of the atmosphere through pores on their leaves called stomata, and simultaneously loose water to the atmosphere through transpiration. These stomata can open and close in response to their environment, changing the conductance of gasses between the interior and exterior of leaves. At the leaf level, plants are observed to close their stomata in response to elevated $\mathrm{CO}_{2}$, thus reducing transpiration fluxes of water [16]. Plants are responding to changes in climate in temperature, water availability, and concentrations of $\mathrm{CO}_{2}$ (green box, Fig. 1). We know that increasing $\mathrm{CO}_{2}$ has the ability to boost photosynthesis, which could increase plant growth, and increase plant water needs. Simultaneously, increasing $\mathrm{CO}_{2}$ allows plants to increase the efficiency at which they trade water for carbon, which could allow them to lose less water while maintaining growth. These two factors counteract one another to influence the total water needs of plants, and thus how they experience water stress. Increasing $\mathrm{CO}_{2}$ will have differential impact on plants with the two most common photosynthetic pathways. Due to their internal leaf structure, plants that use the $\mathrm{C} 4$ photosynthesis pathway (so called for the 4-carbon molecule involved in the biochemistry) experience less of a photosynthetic boost directly from elevated $\mathrm{CO}_{2}$ and thus exhibit less sensitivity in stomatal opening under elevated $\mathrm{CO}_{2}$ concentrations. However, in times of water stress, observations show that $\mathrm{C} 4$ plants still benefit from reduced water loss under elevated $\mathrm{CO}_{2}$ [17]. Plants will also be experiencing novel combinations of environmental conditions not seen in these communities over the past century, and significant uncertainty remains about their ability to withstand drought conditions which are simultaneously hotter than normal.

\section{What will drive drought in the future?}

Climate is changing due to the anthropogenic emissions of greenhouse gasses. This forcing on the climate system has implications not only for temperatures, but also factors that influence both the supply and demand for water from the atmosphere. In addition to this change in water availability, plants are sensitive to changes in the concentration of $\mathrm{CO}_{2}$ in the atmosphere, as well as directly to changes in surface humidity. These multiple competing factors are detailed below, and outlined in Figure 1. 


\section{Supply and Demand}

Simulations of projected changes in precipitation under future climate scenarios vary between models, with little consensus on exact pattern or magnitude changes [18]. The canonical description of precipitation changes under increasing $\mathrm{CO}_{2}$ has been that the "wet get wetter" and the "dry get drier" [19], however this is a poor characterization of the change in pattern of precipitation change over land observed in the historical period [20], or predicted for the future [21-23].

Demand for water by the atmosphere is influenced by increasing temperature [24]. Higher temperatures are associated with a larger vapor pressure deficit (VPD), or the difference in the partial pressure of water in the atmosphere relative to saturated conditions. It is this deficit that actually sets the gradient in water vapor partial pressure and drives rates of evaporation. Due to the non-linearity of the relationship between saturation vapor pressure and temperature (the Clausius-Clapeyron curve) VPD increases with temperature, even if relative humidity stays constant.

Scheff and Frierson [24] attribute the increase of PET in the future primarily to the increasing VPD with temperature, as well as to the increasing slope of the Clausius-Clapeyron curve-the root cause of both being the increase in temperature. In addition to these temperature driven effects at constant relative humidity, future projections suggest that relative humidity will also decrease over land on order of 5 to $10 \%$ under a quadrupling of $\mathrm{CO}_{2}$ from preindustrial values [12]. Thus, PET increases substantially as climate warms. Critically however, increasing PET does not equate to increases in actual ET. In semi-arid regions during present day conditions, the divergence between ET and PET suggests that plants are failing to access sufficient amounts of water to meet atmospheric demand, and is in itself an indicator of drought [13]. However, PET also diverges from ET with increasing $\mathrm{CO}_{2}$, as plants respond physiologically to increasing concentrations of $\mathrm{CO}_{2}$ [12] (discussed further below). Because PET and ET become disconnected due to $\mathrm{CO}_{2}$, the increase in PET is not necessarily related to increasing drought stress experienced by plants, but high VPD could still drive plant stress during extreme events (discussed further below).

\section{What are appropriate drought metrics for the future?}

A large number of drought metrics have been used to asses drought in the future [25], however some are more appropriate than others when assessing drought impacts on plants (Table 1). Given that PET increases as a function of temperature, drought metrics that use PET to estimate water demand show a large scale transition towards drier conditions under hotter temperatures [26-28]. Similarly, assessment of changes to aridity based on the aridity index, which is itself a function of PET, show strong trends towards drier conditions in the future [29-32]. However, because actual ET does not go up as fast as PET [33], this implied drying may not be representing actual plant stress. While metrics that gauge atmospheric demand ("atmospherecentric") show large increases in both drought [26-28] and aridity [27, 29-31, 34-36] under future climate conditions, metrics that account for plant responses to $\mathrm{CO}_{2}$ ("plant-centric" metrics) show more muted responses $[12,37,38]$. In fact, ET stays relatively constant in climate model projections as $\mathrm{CO}_{2}$ rises, even as temperatures increase substantially [12]. ET could be staying more constant because plants lack access to water, in which case it would indicate increased stress, or it could be staying constant because plants are regulating their stomata during 
high VPD conditions due to higher levels of $\mathrm{CO}_{2}$. The former is often invoked as the explanation (e.g. [39]) but individual forcing experiments using Earth system models suggest the latter effect dominates in many regions [12].

Changes in soil moisture should more closely track changes in plant available water and thus should be more appropriate for evaluating plant stress under future conditions. However, as noted before, the actual water available to plants is additional determined by a number of factors which either change in time or are poorly observed at global scales (depth of the rooting zone, root biomass, soil properties including texture and depth, e.g. [13]). Further, we are observationally limited in our ability to validate simulations of soil moisture, especially at large scales. Model consensus suggests that surface soil layers will dry in the future, especially in areas where precipitation is expected to robustly decrease [40, 41]. However, surface soil moisture may not be the most relevant to plants, who's rooting depths reach well below the top $10 \mathrm{~cm}$, the commonly reported depth of soil moisture (e.g. [18]). Deep soil layers do not dry as much as surface soil layers, and in some places even show the opposite sign to the soil above [41]. This is consistent with the idea that plants are using less water under higher $\mathrm{CO}_{2}$ concentrations, and that water may be stored at depth in the soil $[12,42]$.

\section{Carbon Dioxide}

Models of the response of stomatal aperture and photosynthesis to environmental variables (e.g. temperature, VPD, $\mathrm{CO}_{2}$ ) have been derived from leaf level measurements (e.g. [43-47]) and are commonly applied in Earth System Models to represent gas exchange between plants and the environment. Although our leaf level understanding of stomatal response to changing $\mathrm{CO}_{2}$ and other environmental conditions is relatively well constrained by data, our understanding of ecosystem scale response is still uncertain. Actual ET is influenced by both the supply (precipitation) and the demand for water by the atmosphere (PET) but also by plant activity. Plants control the exchange of water between the land surface and the atmosphere through stomatal conductance, and through the number of stomata - a quantity that is closely related to leaf area. The total flux of water from plants (ET) thus takes the form of:

$$
E T \propto \frac{V P D \cdot L A I}{g_{s w}}
$$

Where $V P D$ is the vapor pressure deficit, $L A I$ is the leaf area index, and $g_{s w}$ is the stomatal conductance. Both stomatal conductance and LAI are functions of the total photosynthetic rate (photosynthesis is also a function of stomatal conductance in a coupled sense), and stomatal conductance is additionally directly dependent on the concentration of $\mathrm{CO}_{2}$ in the atmosphere such that higher rates of $\mathrm{CO}_{2}$ lead to less conductance through stomata. LAI and stomatal conductance respond to changing environmental conditions on different timescales, with stomatal conductance responses occurring on timescales of minutes and LAI responses occurring over weeks to months. C3 and C4 plants will also have differing responses, with $\mathrm{C} 4$ plants generally showing less additional growth and less stomatal response, although the responses may still be large during times of water stress. The reduction in stomatal conductance under higher $\mathrm{CO}_{2}$ could be offset by additional growth of leaves through higher rates of photosynthesis, but on a per-leaf basis the rate of ET is lower under higher $\mathrm{CO}_{2}$. This rate of water loss per unit of carbon taken up in photosynthesis is called the Water Use Efficiency (WUE). Increased WUE would afford plants the ability to maintain photosynthesis while using less water, to photosynthesize more while using the same amount of water, or any point between these 
endmembers. Critical to quantifying how much ET will change in the future under higher $\mathrm{CO}_{2}$, is quantifying how much leaf area will increase relative to increasing WUE.

Observational estimates of WUE can be made using direct observations of photosynthesis and ET rates, or through the relative discrimination of ${ }^{13} \mathrm{C}$ compared to ${ }^{12} \mathrm{C}$, or the $\delta{ }^{13} \mathrm{C}$. Records of $\delta$ ${ }^{13} \mathrm{C}$ from tree rings allow us to look back in time at WUE and compare it with present day rates. A number of studies based on tree ring estimates support the finding that WUE increases as $\mathrm{CO}_{2}$ increases [48-50]. In addition to observations of tree rings, which have the potential to be spatially limited or regionally influenced, a bulk estimate of globally averaged WUE can be made from observations of atmospheric $\delta^{13} \mathrm{C}$, and Keeling et al. [51] find that WUE has decreased at about the same rate as indicated by tree ring based studies.

Experiments that use direct manipulation of atmospheric $\mathrm{CO}_{2}$ concentrations in the field, called Free Air $\mathrm{CO}_{2}$ Enrichment experiments (FACE), also find increases in WUE, but do not necessarily see decreases in transpiration [52]. To asses the water budget and thus the availably of water to plants we need to not only understand how WUE responds to $\mathrm{CO}_{2}$ and other factors, but also how transpiration and photosynthesis will change in response to elevated $\mathrm{CO}_{2}$ independent of one another. Climate models do a reasonable job representing the order of magnitude of changes in WUE found in observations over the historical period at forested sites [12], however it is possible that they are still failing to represent the individual changes in photosynthesis and transpiration [52]. The changes in WUE found in two forested FACE experiments show increases of $\sim 30 \%$ in WUE associated with an increase of $\sim 200 \mathrm{ppm}$ in $\mathrm{CO}_{2}$. However the Oak Ridge and Duke FACE experiments differed in the cause for the WUE change, with either decreasing (Oak Ridge) or little change in transpiration (Duke) paired with large (Oak Ridge) to moderate (Duke) increases in photosynthesis [52-54]. FACE experiments are some of the few direct experiments available to test our understanding of whole ecosystem responses to $\mathrm{CO}_{2}$ and provide invaluable insight into multiple competing responses within ecosystems including deserts, croplands, and agricultural crops [55]. Yet they remain limited in location, number (especially for forested systems), and duration such that they are insufficient for fulling testing our ability to model these systems. Satellite data also offers the opportunity to diagnose the response of plants (primarily leaf area) to increasing $\mathrm{CO}_{2}$ over the last few decades, but does not allow us to test our ability to model the response of plants under future $\mathrm{CO}_{2}$ conditions.

The response of plant growth to $\mathrm{CO}_{2}$, in particular increases in leaf area, could compensate for any increases in the efficiency gains of water loss under higher $\mathrm{CO}_{2}$ conditions by increasing the area over which plants will lose water. On a global scale, Earth system models tend to grow more leaf area under future climate conditions but with significant variation across models [56]. However, modeled leaf area increases are not sufficient to compensate for decreased stomatal conductance under large increases in $\mathrm{CO}_{2}[12,57]$, although increases in leaf area could be of sufficient magnitude regionally [58]. Further, significant uncertainty remains in the expected response of leaf growth to increasing $\mathrm{CO}_{2}$, and, if underestimated, could suggest that plant water savings are unlikely to be realized. However, it is primarily asserted the Earth system models are more likely overestimating the leaf area response of plants to $\mathrm{CO}_{2}$, rather that underestimating it. While Earth system models tend to predict increases in photosynthesis and leaf area under future climate [56], many of these models do not represent moderations on increases in photosynthesis 
and growth that may arise from nutrient limitation [59], plant acclimation and adaptation [60], etc.

Calculations of PET, as typically formulated, assume a constant rate of stomatal conductance (i.e. surface conductance is a constant value in the Penman Monteith equation), while in experiments, conductance rates generally decrease under elevated $\mathrm{CO}_{2}$ conditions [55]. The assumption of constant conductance causes calculated PET to increase dramatically in response to climate change because increasing temperatures (and decreasing humidity) imply greater demand from the atmosphere-even if plants can reduce transpiration fluxes because of higher WUE which would moderate the response of actual ET relative to PET. Thus, as $\mathrm{CO}_{2}$ increases, the relationship between PET and actual ET diverges [12]. Because the calculation of PET can't account for any plant-driven responses to $\mathrm{CO}_{2}$, it shows much higher demand for water under a warmer climate, and when included as the "demand" calculation in drought indices, it suggests more severe and more lengthy droughts. However, Swann et al. [12] find that rates of ET increase only slightly in simulations of future climate because stomatal closure more than compensates for increases in leaf area [56] and increases in demand from the atmosphere. Thus, our estimate for future water balance on land depends strongly on our highly uncertain estimate of changes in leaf area.

\section{Humidity}

Drier air increases atmospheric demand for water through increasing VPD. If supply of water is constant, higher VPD leads to increasing drought stress under constant $\mathrm{CO}_{2}$. Observations of the relationship between tree growth and climate in the American Southwest indicate that warm season VPD is the most important factor driving forest drought stress, although cool season precipitation also has substantial predictive power [61]. Energy budget-based calculations of PET account for the demand for water imposed by higher VPD.

Climate model simulations suggest that relative humidity over land will be lower in the future, with drier air thus contributing to higher PET [12]. Increasing temperatures without a subsequent increase in moisture source to the atmosphere would cause both the relative humidity to decrease and the VPD to increase. This simulated drop in relative humidity has been attributed to the contrast in temperature change over land compared to over the ocean [62-64]. However, stomatal closure in response to higher $\mathrm{CO}_{2}$ also decreases the surface ET flux resulting in decreases in the surface level relative humidity both directly, as well as indirectly by increasing surface temperatures due to reduced evaporative cooling and increased sensible heat flux. Swann et al [12] show that on average, half of the drop in surface relative humidity over land is due to plant physiological responses. Thus, simulated future surface humidity already includes influence of stomata as well as any compensating changes in leaf area. When this estimate of humidity is used to calculate PET, the lower humidity leads to the calculation of more severe drought conditions, when, in fact, the lower humidity is actually evidence of plants being less stressed as they are able to maintain rates of productivity with reduced stomatal opening. Using Earth system model estimates of surface humidity to calculate PET and drought indices therefore improperly attributes the drop in humidity, and double counts for the negative impact on plants. 


\section{Plant stress under "hot" droughts}

Droughts in the future will be occurring superimposed on a background of hotter temperatures. While higher $\mathrm{CO}_{2}$ concentrations may boost plant growth and simultaneously help plants conserve water, the co-occurrence of hot conditions during drought could exacerbate plant stress, and potentially lead to increased damage to tissues and higher rates of mortality [65-67]. This increase in plant stress could occur even if drought frequency remains constant and have major impacts on forest structure and functioning in a hotter world [68]. The water saving benefits to plants of high $\mathrm{CO}_{2}$ have the potential to counteract high temperature and VPD which occur during drought events [69]. However, while these effects are likely to be helpful during baseline or average conditions [70-72], but may not be able to compensate during extreme events (e.g. [73]). The water savings plants experience during high $\mathrm{CO}_{2}$ is likely to raise the threshold at which stress and damage occur, but unlikely to alleviate all stress during these extreme events when stomata are already completely closed.

Observations of plants in the field [61, 74], as well as greenhouse [75], growth chamber [76], and model experiments [77] indicate that VPD is a dominant factor in determining mortality during dry events. Concurrent elevations in temperature during drought are likely to increase VPD further, as well as increase metabolic needs of plants [66]. Although experimental evidence is still limited, the existing studies find that hot droughts will kill trees faster [76], suggesting that in the future, even droughts of short duration may prove lethal, leading to more tree killing events even when drought frequency stays constant [68]. However, our mechanistic understanding of the process of mortality is still limited, and this constrains our ability to predict mortality responses to future climate.

Drought stress is damaging to plants both through the direct impacts on hydraulic functioning and through impacts on the ability of the plant to fix sufficient amounts of carbon to meet its metabolic needs. Under water stress, the water potential gradient between the leaves and the roots of a plant becomes large, and under this high gradient, air bubbles can form in the water flow pathways of the plant. This air bubble formation greatly decreases the conductance of water by the plant, a process called cavitation. Tissues that have cavitated are sometimes able to recover, but frequently lose their ability to transport water permanently [78]. This loss of hydraulic functioning impairs a plants ability to transport water, and thus leads to stomatal closure, and possible mortality of the plant. Meta-analysis of trees from across a gradient in rainfall suggests that forests may already be operating close to the limit at which cavitation occurs, leaving them little margin to cope with drier conditions [79].

Plants can also react directly to this increased water demand by closing stomata to avoid cavitation, thus limiting the uptake of carbon through photosynthesis. Through either pathway, if plants fail to fix enough sugars to meet their metabolic needs, they could die. The direct hydraulic damage pathway ("hydraulic failure") and the failure to generate enough carbon to meet metabolic needs ("carbon starvation") are coupled, and both are likely to be amplified under dry conditions which are also hot [80]. A recent synthesis by Adams et al. [81] shows that hydraulic failure almost always occurs associated with tree mortality, whereas carbon reserves were often, but not always, reduced at the time of mortality. There is still significant uncertainty in exactly how mortality occurs, and thus it remains difficult to model [82]. 
Higher rates of mortality during drought could dramatically alter forest structure. The timescales associated with forest growth are significantly longer than those associated with death, such that increased mortality will reduce forest cover much faster than it can regenerate. Changes in forest cover and structure would in turn alter the interactions between the land surface and the atmosphere through impacts on the exchange of energy and water. Loss of forest cover due to mortality increases the surface albedo and simultaneously decreases evapotranspiration rates and increases sensible heating [83]. These alterations of the local surface energy budget can also lead to spatially broad impacts dubbed "ecoclimate teleconnections" by changing both local atmospheric feedbacks such as clouds [84], and large-scale atmospheric circulation patterns through atmospheric wave propagation and alterations in energy gradients [85], with implications for ecosystems far from where the mortality occurred [86-88]. The relatively longer timescale of recovery from mortality could also lead to less plant cover, and thus less regulation by stomata of surface to atmosphere water flux. The mortality response to the hotter droughts expected in the future is a critical uncertainty in determining the impact of future droughts on forests, and is likely to be a major impact independent of any increase in drought frequency.

\section{Conclusions}

How should we asses impacts to plants in a changing climate?

Drought indices such as PDSI are constructed to consider both supply and demand for water from the atmosphere, which is appropriate for assessing plant stress. However, despite considering demand in addition to supply, PDSI relies on a calculation of PET, and metrics that use PET are unstable indicators of plant drought stress under different levels of $\mathrm{CO}_{2}$. PET is not a metric of plant stress, it indicates the water demand from an atmospheric perspective. And because it does not represent changes in plant water needs or physiological responses of plants to changing concentrations of $\mathrm{CO}_{2}$, it is not an appropriate metric of plant stress in the future and gives a misleading impression of future drying over land. In places where the land surface does dry, PET will more closely match ET, and thus will give a more consistent answer. But this does not justify using PET in general, as this will only hold true in places where there is no net effect of plant responses.

Plant stomatal control over water fluxes is of first order relative to other changes expected in the terrestrial water budget in the next century. Plants have the potential to substantially alter surface ET fluxes, both through stomatal regulation, and through changes in plant biomass. This even has substantial impacts on surface relative humidity over land. Uncertainty remains in our understanding of the response of ecosystem-level productivity and thus water fluxes in a future climate. In particular, we lack a mechanistic understanding of the process of mortality, and therefore are limited in our ability to constrain increases in mortality likely to occur during droughts that are also hotter.

Despite these uncertainties, our best estimate that simultaneously considers all of these factors to the best of our ability come from Earth system models. Earth system models include representations of not only atmospheric processes such as changes in dynamics, clouds, and rain, but also land surface processes including plant physiological behavior, plant growth, and subsurface hydrology. Earth system models combine our understanding of these many aspects of the system together, and allow us to quantify the direct interaction and relative impact of 
different factors on drought [89]. Thus, for example, Earth system models can account for the interactions between changing stomatal conductance, leaf area, and surface humidity to asses the net impact of the response to changing $\mathrm{CO}_{2}$. Earth system models also produce a self-consistent estimate of multiple variables simultaneously - avoiding the problem of misinterpreting (and thus double counting) a drop in humidity due to stomatal closure as an indication of more water stress when it could be an indication of less. However, Earth system models remain limited in our ability to represent complex plant processes which are not fully understood, in particular plant mortality. At this stage, they are likely to underestimate plant mortality during drought and the subsequent downstream effects on evapotranspiration, surface climate, and drought.

The balance between improved or reduced success of plants during drought critically depends on the relative magnitude of three factors (Fig. 1): the increase in plant stress when droughts occur, the increase in water needs due to $\mathrm{CO}_{2}$ fertilized growth, both of which have the potential to be partially or entirely alleviated by increased efficiency of water use by plants. In order to quantify the effect of drought on plants in the future, more observational constraints of the response of plants to hot droughts and the limits at which mortality occurs are needed. Further research is needed on the mortality and plant stress response to drought conditions at high temperatures, as well as the differential response of plants to dry soils vs. dry air. Representing these plant processes is critical for assessing the impact of future droughts on plants. Predicting plant responses in the future won't be possible without the ability to model the system which requires an improved mechanistic understanding of the process of mortality. Finally, any improvement in our ability to predict plant growth under high $\mathrm{CO}_{2}$ contributes to our confidence in predicting not only plant responses to future drought, but the occurrence of the drought itself.

\section{Conflict of Interest Statement}

On behalf of all authors, the corresponding author states that there is no conflict of interest.

\section{References}

1. IPCC (2013) Summary for Policymakers. Clim Chang 2013 Phys Sci Basis Contrib Work Gr I to Fifth Assess Rep Intergov Panel Clim Chang 33 . doi:

$10.1017 / \mathrm{CBO} 9781107415324$

2. Glickman (2011) Glossary of Meteorology. Am Meteorol Soc 1:3624-3648

3. Mckee TB, Doesken NJ, Kleist J (1993) The relationship of drought frequency and duration to time scales. AMS 8th Conf Appl Climatol 179-184 . doi: citeulike-articleid: 10490403

4. $\quad$ Palmer WC (1965) Meteorological Drought. U.S. Weather Bur. Res. Pap. No. 4558

5. Alley WM (1984) The Palmer Drought Severity Index: Limitations and Assumptions. J Clim Appl Meteorol 23:1100-1109 . doi: 10.1175/15200450(1984)023<1100:TPDSIL>2.0.CO;2

6. Budyko MI, Miller DH (1974) Climate and life. Academic press New York

7. Thornthwaite CW (1948) An Approach toward a Rational Classification of Climate. Geogr Rev 38:55 . doi: 10.2307/210739

8. Monteith JL (1981) Evaporation and surface temperature. Q J R Meteorol Soc 107:1-27 . doi: 10.1002/qj.49710745102

9. Penman HL (1948) Natural Evporation from Open Water, Bare Soil and Grass. R Soc 
193:120-145 . doi: 10.1098/rspa.1948.0037

10. Sellers PJ, Bounoua L, Collatz GJ, et al (1996) Comparison of radiative and physiological effects of doubled atmospheric CO2 on climate. Science (80- ) 271:1402-1406

11. Wells N, Goddard S, Hayes MJ (2004) A self-calibrating Palmer Drought Severity Index. J Clim 17:2335-2351 . doi: 10.1175/1520-0442(2004)017<2335:ASPDSI>2.0.CO;2

12. Swann ALS, Hoffman FM, Koven CD, Randerson JT (2016) Plant responses to increasing $\mathrm{CO}_{2}$ reduce estimates of climate impacts on drought severity. Proc Natl Acad Sci 113:10019-10024 . doi: 10.1073/pnas.1604581113

13. Stephenson N (1998) Actual evapotranspiration and deficit: biologically meaningful correlates of vegetation distribution across spatial scales. J Biogeogr 25:855-870 . doi: 10.1046/j.1365-2699.1998.00233.x

14. Seneviratne SI, Corti T, Davin EL, et al (2010) Investigating soil moisture-climate interactions in a changing climate: A review. Earth-Science Rev. 99:125-161

15. Clapp RB, Hornberger GM (1978) Empirical equations for some soil hydraulic properties. Water Resour Res 14:601-604 . doi: 10.1029/WR014i004p00601

16. Cowan IR (1977) Stomatal behaviour and environment. Adv Bot Res 4:117-228 . doi: 10.1016/S0065-2296(08)60370-5

17. Leakey ADB (2006) Photosynthesis, Productivity, and Yield of Maize Are Not Affected by Open-Air Elevation of CO2 Concentration in the Absence of Drought. PLANT Physiol 140:779-790 . doi: 10.1104/pp.105.073957

18. Collins M, Knutti R, Arblaster J, et al (2013) IPCC WG1AR5 Chapter 12 Long-term Climate Change: Projections, Commitments and Irreversibility. Clim. Chang. 2013 Phys. Sci. Basis. Contrib. Work. Gr. I to Fifth Assess. Rep. Intergov. Panel Clim. Chang. 10291136

19. Held IM, Soden BJ (2006) Robust responses of the hydrological cycle to global warming. J Clim 19:5686-5699

20. Greve P, Orlowsky B, Mueller B, et al (2014) Global assessment of trends in wetting and drying over land. Nat Geosci 7:716-721 . doi: 10.1038/NGEO2247

21. Roderick ML, Sun F, Lim WH, Farquhar GD (2014) A general framework for understanding the response of the water cycle to global warming over land and ocean. Hydrol Earth Syst Sci 18:1575-1589 . doi: 10.5194/hess-18-1575-2014

22. Byrne MP, O'Gorman P a. (2015) The response of precipitation minus evapotranspiration to climate warming: Why the "wet-get-wetter, dry-get-drier" scaling does not hold over land. J Clim 150904104833007 . doi: 10.1175/JCLI-D-15-0369.1

23. Greve P, Seneviratne SI (2015) Assessment of future changes in water availability and aridity. Geophys Res Lett 42:5493-5499 . doi: 10.1002/2015GL064127

24. Scheff J, Frierson DMW (2014) Scaling potential evapotranspiration with greenhouse warming. J Clim 27:1539-1558 . doi: 10.1175/JCLI-D-13-00233.1

25. Dai A (2011) Drought under global warming: A review. Wiley Interdiscip. Rev. Clim. Chang. 2:45-65

26. Dai A (2013) Increasing drought under global warming in observations and models. Nat Clim Chang 3:52-58

27. Zhao T, Dai A (2015) The magnitude and causes of global drought changes in the 21st century under a low-moderate emissions scenario. J Clim. doi: 10.1175/JCLI-D-1400363.1

28. Cook B, Smerdon J, Seager R, Coats S (2014) Global warming and 21st century drying. 
Clim Dyn 43:2607-2627 . doi: 10.1007/s00382-014-2075-y

29. Sherwood S, Fu Q (2014) Climate change. A drier future? Science (80- ) 343:737-739 . doi: $10.1126 /$ science. 1247620

30. Fu Q, Feng S (2014) Responses of terrestrial aridity to global warming. J Geophys Res Atmos 119:7863-7875

31. Scheff J, Frierson DMW (2015) Terrestrial aridity and its response to greenhouse warming across CMIP5 climate models. J Clim 28:5583-5600 . doi: 10.1175/JCLI-D-1400480.1

32. Berg A, Findell K, Lintner B, et al (2016) Land-atmosphere feedbacks amplify aridity increase over land under global warming. Nat Clim Chang 6:869-874

33. Milly PCD, Dunne KA (2016) Potential evapotranspiration and continental drying. Nat Clim Chang 6:946-949

34. Feng S, Fu Q (2013) Expansion of global drylands under a warming climate. Atmos Chem Phys 13:10081-10094 . doi: 10.5194/acp-13-10081-2013

35. Huang J, Yu H, Guan X, et al (2016) Accelerated dryland expansion under climate change. Nat Clim Chang 6:166-171 . doi: 10.1038/nclimate2837

36. Lin L, Gettelman A, Feng S, Fu Q (2015) Simulated climatology and evolution of aridity in the 21st century. J Geophys Res 120:5795-5815 . doi: 10.1002/2014JD022912

37. Roderick ML, Greve P, Farquhar GD (2015) On the assessment of aridity with changes in atmospheric CO2. Water Resour Res 51:5450-5463 . doi: 10.1002/2015WR017031

38. Greve P, Roderick ML, Seneviratne SI (2017) Simulated changes in aridity from the last glacial maximum to 4xCO2. Environ Res Lett 12:114021

39. Dirmeyer PA, Jin Y, Singh B, Yan X (2013) Trends in Land-Atmosphere Interactions from CMIP5 Simulations. J Hydrometeorol 14:829-849 . doi: 10.1175/JHM-D-12-0107.1

40. Cook BI, Ault TR, Smerdon JE (2015) Unprecedented 21st century drought risk in the American Southwest and Central Plains. Sci Adv 1:e1400082

41. Berg A, Sheffield J, Milly PCD (2017) Divergent surface and total soil moisture projections under global warming. Geophys Res Lett 44:236-244

42. Lemordant L, Gentine P, Stéfanon M, et al (2016) Modification of land-atmosphere interactions by $\mathrm{CO} 2$ effects: implications for summer dryness and heatwave amplitude. Geophys Res Lett 2016GL069896 . doi: 10.1002/2016GL069896

43. Farquhar GD, von Caemmerer S, Berry JA (2001) Models of photosynthesis. Plant Physiol 125:42-45

44. Collatz GJ, Ball JT, Grivet C, Berry JA (1991) Physiological and environmentalregulation of stomatal conductance, photosynthesis and transpiration - a model that includes a laminar boundary-layer. Agric For Meteorol 54:107-136

45. Medlyn BE, Duursma RA, Eamus D, et al (2011) Reconciling the optimal and empirical approaches to modelling stomatal conductance. Glob Chang Biol 17:2134-2144

46. Ball JT, Woodrow IE, Berry JA (1987) A Model Predicting Stomatal Conductance and its Contribution to the Control of Photosynthesis under Different Environmental Conditions. In: Progress in Photosynthesis Research. pp 221-224

47. Leuning R (1995) A critical appraisal of a combined stomatal-photosynthesis model for C3 plants. Plant Cell Environ 18:339-355 . doi: 10.1111/j.1365-3040.1995.tb00370.x

48. van der Sleen P, Groenendijk P, Vlam M, et al (2014) No growth stimulation of tropical trees by 150 years of $\mathrm{CO} 2$ fertilization but water-use efficiency increased. Nat Geosci 8:24-28 . doi: 10.1038/ngeo2313 
49. Peñuelas J, Canadell JG, Ogaya R (2011) Increased water-use efficiency during the 20th century did not translate into enhanced tree growth. Glob Ecol Biogeogr 20:597-608 . doi: 10.1111/j.1466-8238.2010.00608.x

50. Frank DC, Poulter B, Saurer M, et al (2015) Water-use efficiency and transpiration across European forests during the Anthropocene. Nat Clim Chang 5:579-583 . doi: $10.1038 /$ nclimate2614

51. Keeling RF, Graven HD, Welp LR, et al (2017) Atmospheric evidence for a global secular increase in carbon isotopic discrimination of land photosynthesis. Proc Natl Acad Sci 201619240 . doi: 10.1073/pnas.1619240114

52. Kauwe MG, Medlyn BE, Zaehle S, et al (2013) Forest water use and water use efficiency at elevated $\mathrm{CO} 2$ : a model-data intercomparison at two contrasting temperate forest FACE sites. Glob Chang Biol 19:1759-1779

53. Wullschleger SD, Gunderson CA, Hanson PJ, et al (2002) Sensitivity of stomatal and canopy conductance to elevated $\mathrm{CO} 2$ concentration - Interacting variables and perspectives of scale. New Phytol 153:485-496 . doi: 10.1046/j.0028-646X.2001.00333.x

54. Schäfer K, Oren R, Lai C-T, Katul GG (2002) Hydrologic balance in an intact temperate forest ecosystem under ambient and elevated atmospheric $\mathrm{CO}<\mathrm{sub}>2<\mathrm{sub}>$ concentration. Glob Chang Biol 8:895-911 . doi: 10.1046/j.1365-2486.2002.00513.x

55. Ainsworth EA, Long SP (2005) What have we learned from 15 years of free-air CO2 enrichment (FACE)? A meta-analytic review of the responses of photosynthesis, canopy properties and plant production to rising CO2. New Phytol 165:351-372 . doi: 10.1111/j.1469-8137.2004.01224.x

56. Mahowald N, Lo F, Zheng Y, et al (2016) Projections of leaf area index in earth system models. Earth Syst Dynam 7:211-229 . doi: 10.5194/esd-7-211-2016

57. Skinner CB, Poulsen CJ, Chadwick R, et al (2017) The role of plant CO2 physiological forcing in shaping future daily-scale precipitation. J Clim 30:2319-2340 . doi: 10.1175/JCLI-D-16-0603.1

58. Mankin JS, Smerdon JE, Cook BI, et al (2017) The Curious Case of Projected TwentyFirst-Century Drying but Greening in the American West. J Clim 30:8689-8710 . doi: 10.1175/JCLI-D-17-0213.1

59. Wieder WR, Cleveland CC, Smith WK, Todd-Brown K (2015) Future productivity and carbon storage limited by terrestrial nutrient availability. Nat Geosci advance on:

60. Verheijen LM, Aerts R, Brovkin V, et al (2015) Inclusion of ecologically based trait variation in plant functional types reduces the projected land carbon sink in an earth system model. Glob Chang Biol 21:3074-3086 . doi: 10.1111/gcb.12871

61. Williams AP, Allen CD, Macalady AK, et al (2013) Temperature as a potent driver of regional forest drought stress and tree mortality. Nat Clim Chang 3:292-297

62. O'Gorman PA, Muller CJ (2010) How closely do changes in surface and column water vapor follow Clausius-Clapeyron scaling in climate change simulations? Environ Res Lett 5: . doi: 10.1088/1748-9326/5/2/025207

63. Fasullo JT (2010) Robust Land-Ocean Contrasts in Energy and Water Cycle Feedbacks. J Clim 23:4677-4693 . doi: 10.1175/2010JCLI3451.1

64. Joshi MM, Gregory JM, Webb MJ, et al (2008) Mechanisms for the land/sea warming contrast exhibited by simulations of climate change. Clim Dyn 30:455-465 . doi: 10.1007/s00382-007-0306-1

65. Breshears DD, Adams HD, Eamus D, et al (2013) The critical amplifying role of 
increasing atmospheric moisture demand on tree mortality and associated regional die-off. Front Plant Sci 4:266 . doi: 10.3389/fpls.2013.00266

66. Teskey R, Wertin T, Bauweraerts I, et al (2015) Responses of tree species to heat waves and extreme heat events. Plant Cell Environ. 38:1699-1712

67. Matusick G, Ruthrof KX, Brouwers NC, et al (2013) Sudden forest canopy collapse corresponding with extreme drought and heat in a mediterranean-type eucalypt forest in southwestern Australia. Eur J For Res 132:497-510 . doi: 10.1007/s10342-013-0690-5

68. Allen CD, Breshears DD, McDowell NG (2015) On underestimation of global vulnerability to tree mortality and forest die-off from hotter drought in the Anthropocene. Ecosphere 6:art129 . doi: 10.1890/ES15-00203.1

69. Liu Y, Parolari AJ, Kumar M, et al (2017) Increasing atmospheric humidity and $\mathrm{CO}_{2}$ concentration alleviate forest mortality risk. Proc Natl Acad Sci 201704811 . doi: 10.1073/pnas.1704811114

70. Novick KA, Ficklin DL, Stoy PC, et al (2016) The increasing importance of atmospheric demand for ecosystem water and carbon fluxes. Nat Clim Chang advance on:

71. Sulman BN, Roman DT, Yi K, et al (2016) High atmospheric demand for water can limit forest carbon uptake and transpiration as severely as dry soil. Geophys Res Lett 43:96869695 . doi: 10.1002/2016GL069416

72. Ficklin DL, Novick KA (2017) Historic and projected changes in vapor pressure deficit suggest a continental-scale drying of the United States atmosphere. J Geophys Res 122:2061-2079 . doi: 10.1002/2016JD025855

73. Duan H, Duursma RA, Huang G, et al (2014) Elevated CO_2 does not ameliorate the negative effects of elevated temperature on drought-induced mortality in Eucalyptus radiata seedlings. Plant Cell Environ 37:1598-1613 . doi: 10.1111/pce.12260

74. Breshears DD, Cobb NS, Rich PM, et al (2005) Regional vegetation die-off in response to global-change-type drought. Proc Natl Acad Sci U S A 102:15144-15148

75. Adams HD, Guardiola-Claramonte M, Barron-Gafford GA, et al (2009) Temperature sensitivity of drought-induced tree mortality portends increased regional die-off under global-change-type drought. Proc Natl Acad Sci 106:7063-7066 . doi: 10.1073/pnas.0901438106

76. Adams HD, Barron-Gafford GA, Minor RL, et al (2017) Temperature response surfaces for mortality risk of tree species with future drought. Environ Res Lett 12:115014

77. Eamus D, Boulain N, Cleverly J, Breshears DD (2013) Global change-type droughtinduced tree mortality: Vapor pressure deficit is more important than temperature per se in causing decline in tree health. Ecol Evol 3:2711-2729 . doi: 10.1002/ece3.664

78. Brodribb TJ, McAdam S a M (2015) Evolution in the smallest valves (stomata) guides even the biggest trees. Tree Physiol 35:451-452 . doi: 10.1093/treephys/tpv042

79. Choat B, Jansen S, Brodribb TJ, et al (2012) Global convergence in the vulnerability of forests to drought. Nature 491:752+ . doi: 10.1038/nature11688

80. McDowell N, Pockman WT, Allen CD, et al (2008) Mechanisms of plant survival and mortality during drought: why do some plants survive while others succumb to drought? New Phytol 178:719-739

81. Adams HD, Zeppel MJB, Anderegg WRL, et al (2017) A multi-species synthesis of physiological mechanisms in drought-induced tree mortality. Nat Ecol Evol 1:1285-1291 . doi: 10.1038/s41559-017-0248-x

82. McDowell NG, Beerling DJ, Breshears DD, et al (2011) The interdependence of 
mechanisms underlying climate-driven vegetation mortality. Trends Ecol Evol 26:523532

83. Villegas JC, Law DJ, Stark SC, et al (2017) Prototype campaign assessment of disturbance-induced tree loss effects on surface properties for atmospheric modeling. Ecosphere 8: . doi: 10.1002/ecs2.1698

84. Laguë MM, Swann ALS (2016) Progressive Midlatitude Afforestation: Impacts on Clouds, Global Energy Transport, and Precipitation. J Clim 29:5561-5573 . doi: 10.1175/JCLI-D-15-0748.1

85. Swann ALS, Fung IY, Chiang JCH (2012) Mid-latitude afforestation shifts general circulation and tropical precipitation. Proc Natl Acad Sci 109:712-716 . doi: 10.1073/pnas.1116706108

86. Garcia ES, Swann ALS, Villegas JC, et al (2016) Synergistic ecoclimate teleconnections from forest loss in different regions structure global ecological responses. PLoS One 11: . doi: 10.1371/journal.pone.0165042

87. Stark SC, Leitold V, Wu JL, et al (2012) Amazon forest carbon dynamics predicted by profiles of canopy leaf area and light environment. Ecol Lett 15:1406-1414

88. Swann ALS, Laguë MM, Garcia ES, et al (2018) Continental-scale Consequences of Tree die-offs in North America: Identifying Where Forest Loss Matters Most. Environ Res Lett in press:

89. Bonan GB, Doney SC. Climate, ecosystems, and planetary futures: The challenge to predict life in Earth system models. Science. 2018;359(6375):eaam8328.

https://doi.org/10.1126/science. aam8328. 
Figures

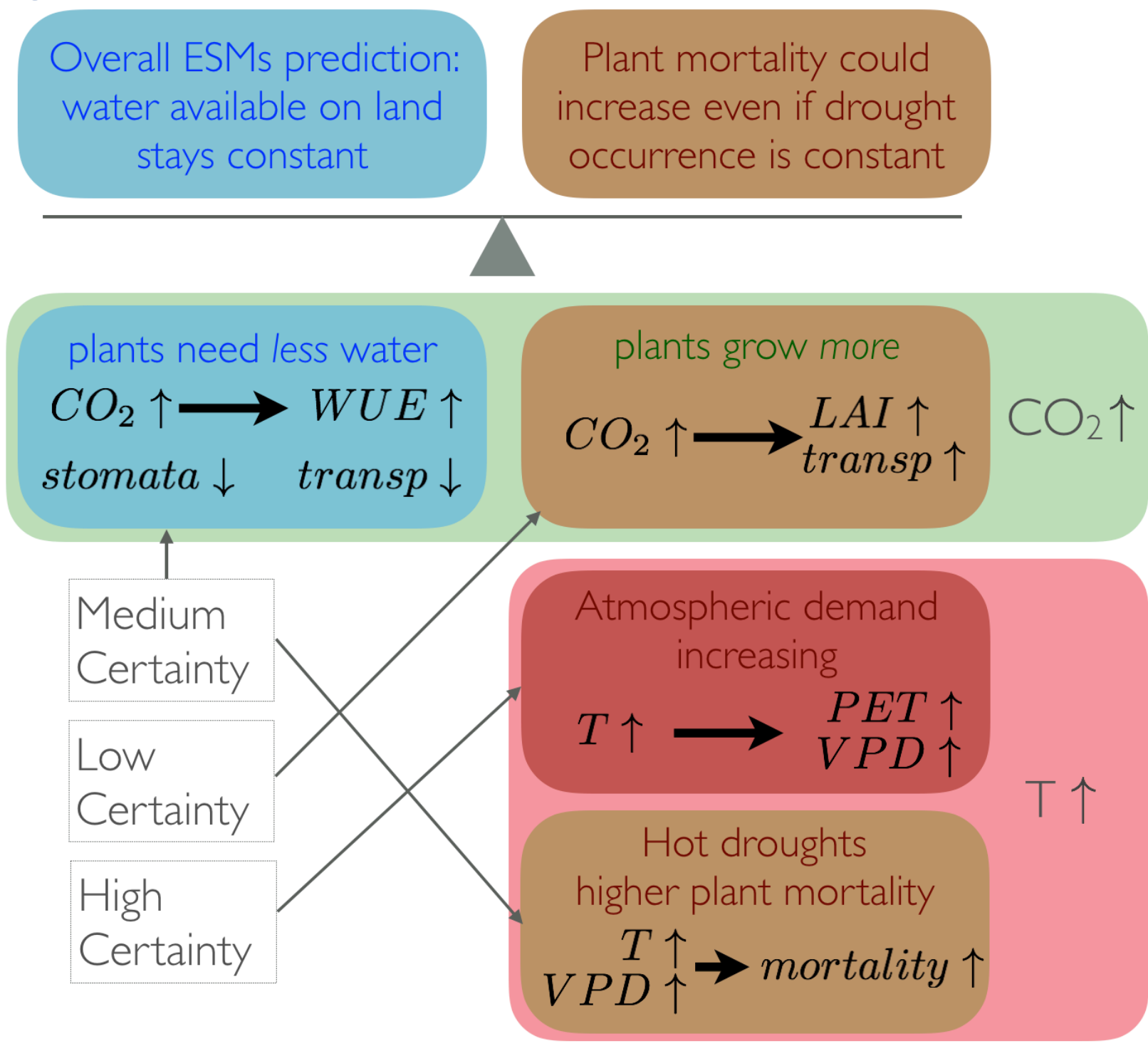

Figure 1. Schematic showing the balance between different factors influencing plants under future drought. Blue boxes indicate factors which alleviate drought stress, while brown boxes indicate factors which increase drought stress. The green box indicates factors driven by concentrations of $\mathrm{CO}_{2}$, the red box indicates factors driven by increasing temperature. The response of VPD to increasing temperature is highly certain, while the response of stomata and WUE to increasing $\mathrm{CO}_{2}$ are well characterized at the leaf scale, but less well known at the ecosystem scale. There is likely to be higher mortality under future climate conditions, however the net impact is still unknown, placing it in the medium certainty category. The ecosystemlevel response of leaf area growth is the least certain of the processes listed here. 


\section{Tables}

Table 1. Metrics of Drought and Dryness characterized by if they only consider deficits in the supply of water ("Supply only", left column), if they do not allow for surface conductance to change in response to increasing $\mathrm{CO}_{2}$ ("Atmosphere-centric", middle column) and if they explicitly include the influence of atmospheric $\mathrm{CO}_{2}$ on plant processes and evapotranspiration ("Plant-centric", right column).

\begin{tabular}{|l|l|l|}
\hline Supply only & "Atmosphere-centric" & "Plant Centric" \\
\hline $\begin{array}{l}\text { Standardized Precipitation } \\
\text { Index (SPI) }\end{array}$ & $\begin{array}{l}\text { Palmer Drought Severity Index } \\
\text { (PDSI) }\end{array}$ & Runoff Deficit Index \\
\hline Rainfall deciles & Aridity (P/PET) & Soil Moisture (from a model) \\
\hline & $\begin{array}{l}\text { Standardized Precipitation } \\
\text { Evapotranspiration Index (SPEI) }\end{array}$ & Total Water Deficit \\
\hline & Z-index from Palmer & Surface Water Supply \\
\hline & Palmer hydrologic drought index & Water Budget (P-E) \\
\hline
\end{tabular}

